\title{
Sistem Pendukung Keputusan Menggunakan Metode Weighted Product untuk Pemilihan Karyawan Terbaik UMKM ZainToppas
}

\author{
Ardi Cahyadi Yudistira ${ }^{[1]}$, Yunita Sartika Sari ${ }^{[2]}$ \\ Program Studi Sistem Informasi ${ }^{[1],[2]}$ \\ Universitas Mercu Buana ${ }^{[1],[2]}$ \\ Jakarta, Indonesia \\ e-mail: 41816110184@student.mercubuana.ac.id ${ }^{[1]}$,yunita.sartika@mercubuana.ac.id ${ }^{[2]}$
}

\begin{abstract}
Every company needs employees as a force that runs every activity in the corporate organization. In order to achieve the targets that have been compiled by the management, all employees should show maximum performance, therefore to improve the performance of employees so that the targets that have been drafted can be achieved, UMKM ZainToppas will give reward to the best employees that have been chosen, but in the selection of best employees ZainToppas has to implement the right decision support Based on this, it will be built a decision support system by using method weighted product to solve problems that occur in UMKM ZainToppas for the selection of the best employees who are entitled to receive reward in accordance with criteria-criteria that have been determined and more objective. The development of the system using waterfall method and scanning method of weighted product, the output of this system is an alternative that has the highest $v$ vector value, the intended alternative is the employee, then the employee is entitled to receive the reward as the best employee.
\end{abstract}

Keywords-Decision support System, Waterfall, Weighted Product

Abstrak- Setiap perusahaan membutuhkan karyawan sebagai tenaga yang menjalankan setiap aktivitas yang ada dalam organisasi perusahaan. Demi mencapai target - target yang telah disusun oleh manajemen, semua karyawan harus menunjukann kinerja yang maksimal, oleh karena itu untuk meningkatkan kinerja karyawan agar target - target yang telah disusun dapat di capai , UMKM ZainToppas akan memberikan reward kepada karyawan terbaik yang telah dipilih, namun dalam pemilihan karyawan terbaik UMKM ZainToppas harus mengimplementasikan sistem pendukung keputusan yang tepat agar lebih objektif. Berdasarkan hal tersebut maka akan dibangunlah sistem pendukung keputusan dengan menggunakan metode weighted product guna memecahkan permasalahan yang terjadi pada UMKM ZainToppas agar pemilihan karyawan terbaik yang berhak menerima reward sesuai dengan kriteria kriteria yang telah ditentukan dan lebih objektif. Pembangunan sistem tersebut menggunakan metode waterfall dan pengimpelentasian metode weighted product, hasil keluaran dari sistem ini adalah alternatif yang memiliki nilai vektor $\mathrm{v}$ tertinggi, alternatif yang dimaksudkan adalah karyawan, maka karyawan tersebutlah yang berhak menerima reward sebagai karyawan terbaik.
Kata Kunci- Sistem Pendukung Keputusan, Waterfall, Weighted Product

\section{PENDAHULUAN}

Setiap perusahaan membutuhkan karyawan sebagai tenaga yang menjalankan setiap aktivitas yang ada dalam organisasi perusahaan, dalam hal tersebut karyawan sebagai sumber daya manusia adalah aset terpenting yang dimiliki oleh perusahaan.

Dikarenakan karyawan adalah aset bagi perusahaan, maka harus terjalin hubungan yang baik antara karyawan dengan perusahaan. Menurut[1] di dalam penelitian yang telah dilakukan kepada karyawan Divisi produksi PT. BI di Gresik dapat diketahui terdapat hubungan yang positif sangat signifikan antara kepemimpinan transformasional dan kepuasan kerja dengan komitmen organisasi, sedangkan secara sendiri-sendiri terdapat hubungan yang positif antara kepemimpinan transformasional dengan komitmen organisasi, dan terdapat hubungan yang positif signifikan antara kepuasan kerja dengan komitmen organisasi.

Menurut[2]Pimpinan hendaknya mengarahkan program yang akan ditempuh dalam usaha pencapaian tujuan. Pemimpin harus bisa menjadi komunikator yang efektif, mediator yang andal khususnya dalam hubungan ke dalam, terutama dalam menangani situasi konflik. Pimpinan harus bisa menjadi integrator yang efektif, rasional, objektif dan netral. Hal tersebut tidak hanya berlaku untuk perusahaan besar saja, berlaku pula untuk usaha mikro, kecil dan menengah (UMKM).

Usaha mikro dan menengah memiliki peran penting dalam pengembangan dan pertumbuhan ekonomi[3] negara, dan menjadi sumber pemasukan untuk karyawan serta pemilik UMKM tersebut, maka demi keberlangsungan usaha tersebut harus adanya hubungan yang baik antara karyawan dan pemilik usaha

UMKM ZainToppas adalah UMKM yang bergerak dibidang penjualan bahan pembersih piring, pewangi pakaian dan pembersih lantai yang melakukan proses bisnisnya melalui penjualan online ,terjun langsung untuk menawarkan produknya kepada masyarakat dan mengikuti bazar produk. hal tersebut dilakukan guna mencapai target - target manajemen yang telah di susun oleh UMKM ZainToppas, 
maka target - target yang telah di susun tersebut harus di seimbangkan dengan kinerja karyawan yang baik. Berdasarkan penelitian yang telah dilakukan kepada UMKM ZainToppas, hal yang menyebabkan tidak tercapainya target target yang telah disusun disebabkan tidak maksimalnya kinerja karyawan antara lain, ditemukannya beberapa karyawan yang terlambat masuk kerja, staf sales yang melakukan pemasaran produk kepada masyarakat ataupun mengikuti bazar produk masih ditemukan tidak mengikuti SOP (Standar Operasional Prosedur) sehingga target penjualan yang telah ditetapkan sebelumnya tidak mencapai target.

Berdasarkan permasalahan yang ada, maka diperlukannya faktor - faktor pemicu kinerja karyawan menjadi lebih baik dan maksimal, pada penelitian[4] hasil uji hipotesis pengaruh reward terhadap kinerja karyawan menghasilkan angka positif dan signifikan mengindikasikan bahwa semakin baik reward di perusahaan, maka akan semakin meningkatkan kinerja karyawan. Sebaliknya, semakin tidak baik reward di perusahaan, maka akan semakin menurunkan kinerja karyawan. Mengacu pada penelitian tersebut maka UMKM ZainToppas akan mengimplementasikan pemberian reward berupa insentif kepada karyawan, namun pemberian insentif harus memenuhi kriteria - kriteria yang ditentukan oleh Owner UMKM ZainToppas, diperlukannya sistem pendukung keputusan sehingga pemberian reward lebih objektif.

Sistem pendukung keputusan adalah teknologi dan aplikasi yang dapat membantu pembuat keputusan dalam menyusun informasi yang berguna dari data mentah terkait untuk mengidentifikasi dan menyelesaikan masalah. Komponen utama DSS cocok data, model, pengetahuan yang diperoleh dari pemodelan data, dan antarmuka pengguna[5]. Pada penelitian ini akan menggunakan metode weighted product . Metode Weighted Product adalah metode yang menggunakan multiplikasi untuk menghubungkan peringkat atribut, di mana setiap peringkat atribut harus dikalikan terlebih dahulu ke bobot yang bersangkutan atribut[6].

Mengacu pada penelitian yang dilakukan oleh dona dan kawan-kawan yang membahas tentang sistem pendukung keputusan karyawan terbaik Menggunakan metode weight product Universitas Pasir Pengaraian[7], yang berguna untuk memilih karyawan terbaik dengan menggunakan metode weight product, dalam penelitian ini kriteria - kriteria sudah ditentukan sebelumnya dan hanya menangani satu pemilihan karyawan saja, dan penelitian yang dilakukan oleh Irfan Ardhiyanto dan kawan - kawan yang membahas tentang implementasi metode weighted product pada sistem pendukung keputusan penilaian karyawan terbaik di Pandanaran Hotel Semarang[8] serupa dengan penelitian yang dilakukan oleh Dona dan Kawan - kawan ,penelitian ini sudah menentukan kriteria - kriteria yang akan digunakan dalam metode weighted product . Pada penelitian ini kali ini penulis akan mengembangkan penelitian yang dilakukan pada penelitian terdahulu dengan memasukan sub - sub kriteria sehingga sistem pendukung keputusan akan menjadi lebih terperinci dan tepat sasaran. Sistem pendukung keputusan ini akan di implementasikan kepada UMKM ZainToppas dalam memilih karyawan terbaik.

\section{LANDASAN TEORI}

\section{A. Sistem Pendukung Keputusan}

Sistem Pendukung Keputusan (SPK) adalah suatu sistem informasi spesifik yang ditujukan untuk membantu manajemen dalam mengambil keputusan yang berkaitan dengan persoalan yang bersifat semi terstruktural. Sistem ini memiliki fasilitas untuk menghasilkan berbagai alternatif yang secara interaktif digunakan oleh pemakai[9][10].

Menurut[11] Sistem pendukung keputusan memungkinkan pengambil keputusan untuk menghasilkan keputusan dalam waktu yang lebih cepat (efisiensi waktu) karena duksungan sistem dapat memproses data dalam jumlah yang besar dengan cepat dan dapat menghasilkan keputusan yang sesuai dengan tujuan (efisien).

\section{B. Weighted Product}

Metode Weighted Product serupa dengan metode Weighted Sum Model (WSM) dan juga disebut sebagai Multiplicative Exsponent Weighting (MEW). Ini adalah satu lagi Metode skoring MADM, perbedaan utamanya adalah bukannya penambahan seperti biasanya pada operasi matematika namun sekarang itu adalah perkalian. Seperti semua metode MADM, weight product adalah himpunan berhingga dari alternatif keputusan yang dijelaskan dalam hal beberapa kriteria keputusan[12].

Langkah-langkah yang dilakukan dalam penyelesaian masalah menggunakan metode weighted product adalah

\section{1) Normalisasi atau Perbaikan Bobot}

$W j=\frac{W j}{\sum W j}$.

Melakukan normalisasi atau perbaikan bobot untuk menghasilkan nilai $\mathrm{Wj}=1$, dimana $j=1,2, \ldots \ldots, \mathrm{n}$ adalah banyak alternatif dan $\sum \mathrm{Wj}$ adalah jumlah keseluruhan nilai bobot.

\section{2) Menentukan Nilai Vektor $S$}

$S i=\prod_{j=1}^{n} X_{i j}^{w j}$

Menentukan nilai vektor $\mathrm{S}$ dengan cara mengalikan seluruh kriteria dengan alternatif hasil normalisasi atau perbaikan bobot yang berpangkat positif untuk kriteria keuntungan (benefit) dan yang berpangkat negatif untuk kriteria biaya (cost). Dimana S merupakan preferensi kriteria, $x$ merupakan nilai kriteria dan $n$ merupakan banyaknya kriteria.

\section{3) Menentukan Nilai Vektor $V$}

$V i=\frac{\prod_{j=1}^{n} X_{i j}^{w j}}{\prod_{j=1}^{n}\left(X_{j}^{w}\right)^{w j}}$.

Menentukan nilai vektor $\mathrm{V}$ dimana vektor $\mathrm{V}$ merupakan prefernsi alternatif yang akan digunakan untuk perankingan dari masing-masing jumlah nilai vektor $\mathrm{S}$ dengan jumlah seluruh nilai vektor $\mathrm{S}$.

\section{Metode Waterfall}

Metode air terjun atau yang sering disebut metode waterfall sering dinamakan siklus hidup klasik (classic life cycle), 
dimana hal ini menggambarkan pendekatan yang sistematis dan juga berurutan pada pengembangan perangkat lunak [16].

\section{METODE PENELITIAN}

Metodologi penelitian merupakan suatu perencanaan penelitian yang akan dilakukan secara sistematis dan ilmiah.

\section{A. Lokasi Penelitian}

Nama Tempat : Alamat

$$
\begin{aligned}
& \text { Kantor ZainToppas } \\
& \text { Jalan At Taqwa No.8, Jelupang, } \\
& \text { Kecamatan Serpong Utara, Kota } \\
& \text { Tangerang Selatan, Banten } \\
& \text { 15323. }
\end{aligned}
$$

\section{B. Sarana Pendukung}

Perangkat Lunak

Notepad++ , Google chrome, Codeigniter, Php, Java, Android Studio.

Perangkat Keras : Hp Probook 4340 s, Ram 6 GB

\section{Teknik Pengumpulan Data}

1) Observasi (Pengamatan langsung)

Penulis melakukan pengamatan langsung ke tempat objek pembahasan yang ingin diperoleh yaitu melalui bagianbagian terpenting di ZainToppas

\section{2) Wawancara}

Penulis melakukan interview (wawancara) untuk mendapatkan penjelasan dari masalah-masalah yang sebelumnya kurang jelas dan untuk menyakinkan bahwa data yang diperoleh benar- benar akurat. Dimana penulis melakukan interview kepada Pihak ZainToppas.

3) Library Research

Metode ini penulis mengutip dari beberapa bacaan yang berkaitan dengan pelaksanaan Penelitian yang dilaksanakan di ZainToppas

\section{Diagram Alir Penelitian}

\section{1) Analisa Kebutuhan}

Dalam proses ini, analisa kebutuhan merupakan sebuah proses untuk mendapatkan informasi dan memahami dengan sebenar-benarnya kebutuhan dalam pembuatan sistem.

\section{2) Pengumpulan Data}

Pada tahap ini dilakukan pengumpulan data yang berhubungan dengan penelitian. Dalam tahap ini, penyusun melakukan pengumpulan data dengan cara melakukan wawancara terhadap user maupun departemen terkait dan melakukan observasi dan studi literature.

\section{3) Perancangan Aplikasi}

Pada tahap ini dilakukan perhitungan manual metode weighted product berdasarkan kriteria yang dihasilkan pada saat wawancara dengan user dan merancang serta desain aplikasi.

\section{4) Pembuatan Aplikasi}

Setelah tahap perancangan dilakukan, tahap selanjutnya pembuatan aplikasi. Dimana proses ini menyesuaikan dengan data yang diperoleh dan kebutuhan dari user.

\section{5) Perbaikan Aplikasi}

Pada tahap ini , apabila aplikasi yang sudah dibuat. Maka tahap selanjutnya perbaikan aplikasi jika aplikasi tersebut tidak sesuai dengan kebutuhan user.

\section{6) Implementasi Aplikasi}

Pada tahap ini, desain perangkat lunak diwujudkan dalam bentuk unit-unit program.

\section{7) Testing Aplikasi}

Tahap ini bertujuan untuk memastikan bahwa setiap unit program dibuat sesuai dengan spesifikasinya.

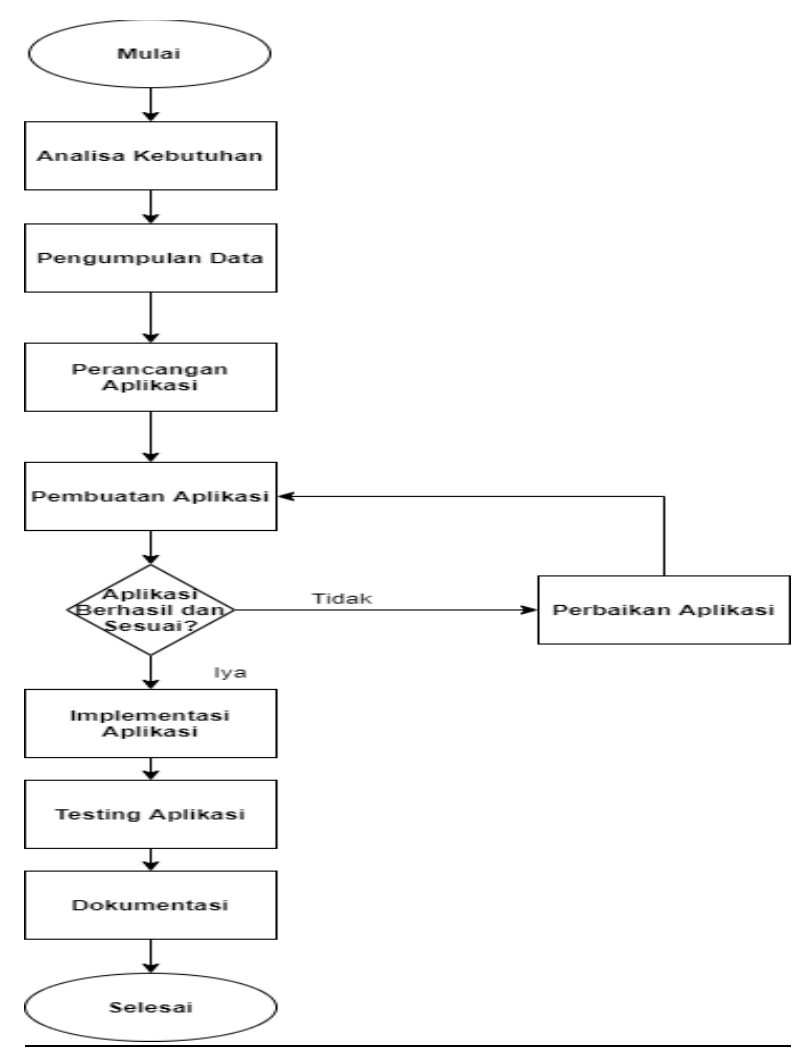

Gambar 1. Diagram Alir Penelitian

\section{ANALISIS DAN PEMBAHASAN}

\section{A. Analisa Kebutuhan dan Pengumpulan data.}

Berdasarkan hasil wawancara dengan Owner UMKM ZainToppas, observasi secara langsung dan studi literature menghasilkan sistem pendukung keputusan dengan metode weighted product guna menyelesaikan masalah yang terjadi pada UMKM Zain Toppas. 


\section{B. Perancangan dan Pembuatan Aplikasi.}

Pada tahap ini sebelum merancang dan membuat aplikasi ,maka dilakukannya perhitungan metode weighted product Berdasarkan data yang di dapat dari hasil analisa kebutuhan dan pengumpulan data.

Perhitungan ini menjadi landasan sistem dalam menghasilkan keluaran alternatif yang memiliki nilai tertinggi dibandingkan dengan alternatif nilai yang lain.

\section{1) Perhitungan Weighted Product}

Keluaran yang dihasilkan dari perhitungan ini adalah sebuah alternatif yang memiliki nilai tertinggi dibandingkan dengan alternatif nilai yang lain. Hasil akhir yang dikeluarkan oleh sistem berasal dari setiap kriteria, subkriteria, karena dalam setiap kriteria dan subkriteria memiliki nilai yang berbeda-beda. Alternatif yang dimaksud adalah karyawan, Kebutuhan informasi merupakan kebutuhan yang ada pada sistem dan informasi yang dihasilkan oleh sistem. Kebutuhan informasi pada sistem pendukung keputusan pemilihan karyawan terbaik memiliki lima tahapan proses untuk mendapatkan hasil rekomendasi karyawan terbaik mendapatkan hasil rekomendasi karyawan terbaik.

\section{a) Tahapan Pertama}

Menentukan kriteria dalam pemilihan karyawan terbaik dan memberikan bobot serta melakukan perbaikan bobot pada setiap kriteria, kriteria tersebut di antaranya :

1. Pekerjaan

2. Kepribadian

Tabel 1. Bobot Nilai Kriteria

\begin{tabular}{|c|c|}
\hline Kriteria & Bobot \\
\hline Pekerjaan & 5 \\
\hline Kepribadian & 4 \\
\hline
\end{tabular}

Pada Tabel 1, dimana bobot pada kriteria adalah

$$
\begin{array}{ll}
1=\text { Sangat rendah } & 4=\text { Tinggi } \\
2=\text { Rendah } & 5=\text { Tinggi Sekali }
\end{array}
$$

$3=$ Cukup

Selanjutnya melakukan perbaikan bobot pada

setiap kriteria dengan meggunakan rumus sebagai sebagai berikut.

$W j=\frac{W j}{\sum W j}$ dengan $W j$ adalah nilai bobot.

$W_{1}=\frac{5}{5+4}=0.555555556$

$W_{1}=\frac{4}{5+4}=0.444444444$

Tabel 2 Perbaikan Bobot Nilai Kriteria

\begin{tabular}{|c|c|c|}
\hline Kriteria & Bobot & Hasil Perbaikan Bobot \\
\hline Pekerjaan & $5 / 9$ & 0.555555556 \\
\hline Kepribadian & $4 / 9$ & 0.444444444 \\
\hline
\end{tabular}

b) Tahapan Kedua

Menentukan subkriteria pada masing-masing kriteria dan menentukan bobot serta melakukan perbaikan bobot pada masing masing subkriteria,selanjutnya menentukan nilai bobot global, subkriteria tersebut antara lain.

A) Kriteria Pekerjaan :

1. Kerjasama Tim

2. Pencapaian Target

3. Tepat Waktu

B) Kriteria Kepribadian :

1. Sopan

2. Sikap SOP (Standar Operasional Prosedur)

Tabel 3 Bobot Nilai Sub Kriteria

\begin{tabular}{|c|c|c|}
\hline Kriteria & SubKriteria & Bobot \\
\hline \multirow{3}{*}{ Pekerjaan } & Kerjasama Tim & 5 \\
\cline { 2 - 3 } & Pencapaian Target & 4 \\
\cline { 2 - 3 } & Tepat Waktu & 3 \\
\hline Kepribadian & Sopan & 4 \\
\cline { 2 - 3 } & Sikap SOP & 5 \\
\hline
\end{tabular}

Selanjutnya melakukan perbaikan bobot pada setiap sub kriteria dan menentukan nilai bobot global sebagai berikut:

Tabel 4 Perbaikan bobot nilai subkriteria dan menentukan bobot global
\begin{tabular}{|c|c|c|c|c|}
\hline Kriteria & SubKriteria & Bobot & $\begin{array}{c}\text { Hasil } \\
\text { Perbaikan } \\
\text { bobot }\end{array}$ & $\begin{array}{c}\text { Bobot } \\
\text { global }\end{array}$ \\
\hline Pekerjaan & Kerjasama Tim & $5 / 12$ & 0.4166666 & 0.2314 \\
& & & 67 & 81481 \\
\hline \multirow{4}{*}{ Kepribadian } & Pencapaian & $4 / 12$ & 0.3333333 & 0.1851 \\
& Target & & 33 & 85185 \\
\cline { 2 - 5 } & Tepat Waktu & $3 / 12$ & 0.25 & 0.1388 \\
& Sopan & $4 / 9$ & 0.4444444 & 0.1975 \\
& & & 44 & 30864 \\
\cline { 2 - 5 } & Sikap SOP & $5 / 9$ & 0.5555555 & 0.2469 \\
& & & 56 & 1358 \\
\hline
\end{tabular}

Pada tabel 4 , bobot global didapat dari hasil perkalian hasil perbaikan bobot kriteria dengan hasil perbaikan bobot subkriteria.

\section{c) Tahapan Ketiga}

Pada tahap ini adalah menentukan data alternatif dan mengisi nilai data alternatif untuk rekomendasi karyawan terbaik, dan datanya sebagai berikut.

\begin{tabular}{|c|c|c|c|c|c|}
\hline \multicolumn{1}{|c|}{ Tabel 5 Data alternatif beserta nilai } \\
\hline $\begin{array}{c}\text { Nama } \\
\begin{array}{c}\text { Pencap } \\
\text { aian } \\
\text { Target }\end{array}\end{array}$ & $\begin{array}{c}\text { Kerjasama } \\
\text { Tim }\end{array}$ & $\begin{array}{c}\text { Tepat } \\
\text { Waktu }\end{array}$ & Sopan & SOP \\
\hline M.Yosril & 90 & 85 & 85 & 85 & 85 \\
\hline $\begin{array}{c}\text { Ardi } \\
\text { Cahyadi }\end{array}$ & 87 & 90 & 88 & 90 & 87 \\
\hline Rusdiana & 95 & 85 & 85 & 90 & 83 \\
\hline
\end{tabular}

\section{d) Tahapan Keempat}

Kemudian mencari nilai S setiap subkriteria dari alternatif dipangkatkan dengan bobot global sesuai dengan subkriteria masing-masing. 
$S i=\prod_{j=1}^{n} X_{i j}^{w j}$

Keterangan:

$\mathrm{S}=$ preferensi alternatif

$\mathrm{W}=$ bobot kriteria

$\mathrm{X}=$ nilai kriteria $\mathrm{i}=$ alternatif ke-i sampai dengan $\mathrm{n}$

$\mathrm{j}=$ kriteria

1. M.Yosril $\mathrm{S} 1=\left(90^{0.23148}\right) \cdot\left(85^{0.18519}\right) \cdot\left(85^{0.13889}\right) \cdot\left(85^{0.19753}\right) \cdot\left(85^{0.24691}\right)=$ 86.1321105

2. Ardi Cahyadi Y $\mathrm{S} 2=\left(87^{0.23148}\right) \cdot\left(90^{0.18519}\right) \cdot\left(88^{0.13889}\right) \cdot\left(90^{0.19753}\right) \cdot\left(87^{0.24691}\right)=$ 88.27617497

3. Rusdiana $\mathrm{S} 3=\left(95^{0.23148}\right) \cdot\left(85^{0.18519}\right) \cdot\left(88^{0.13889}\right) \cdot\left(90^{0.19753}\right) \cdot\left(83^{0.24691}\right)=$ 87.69011513

e) Tahapan Kelima

Tahap kelima dilakukan perankingan atau mencari nilai $\mathrm{V}$ dengan cara penjumlahan dari hasil perkalian nilai vektor $S$ dikali dengan setiap alternatif normalisasi nilai vektor $\mathrm{S}$.

$V i=\frac{\prod_{j=1}^{n} X_{i j}^{w j}}{\prod_{j=1}^{n}\left(X_{j}^{w}\right)^{w j}}$

Jadi Hasil dari menghitung preferensi (Vi) adalah sebagai berikut:

1. M.Yosril

$\mathrm{V}=(86.1321105) / 86.1321105+88.27617497+87.6901$

$1513=0.32862509$

2. Ardi Cahyadi $\mathrm{V}=(88.27617497) / 86.1321105+88.27617497+87.690$ $11513=0.33680547$

3. Rusdiana $\mathrm{V}=(87.69011513) / 86.1321105+88.27617497+87.690$ $11513=0.33456944$

Dari hasil tersebut dapat di simpulkan bahwa alternatif karyawan terbaik adalah Ardi Cahyadi dengan $\mathrm{V}=$ 0.33680547

2) Perancangan Aplikasi

Kegiatan yang dilakukan pada tahap ini yaitu merancang usecase diagram usulan pada gambar 2 dan class diagram pada gambar 3.
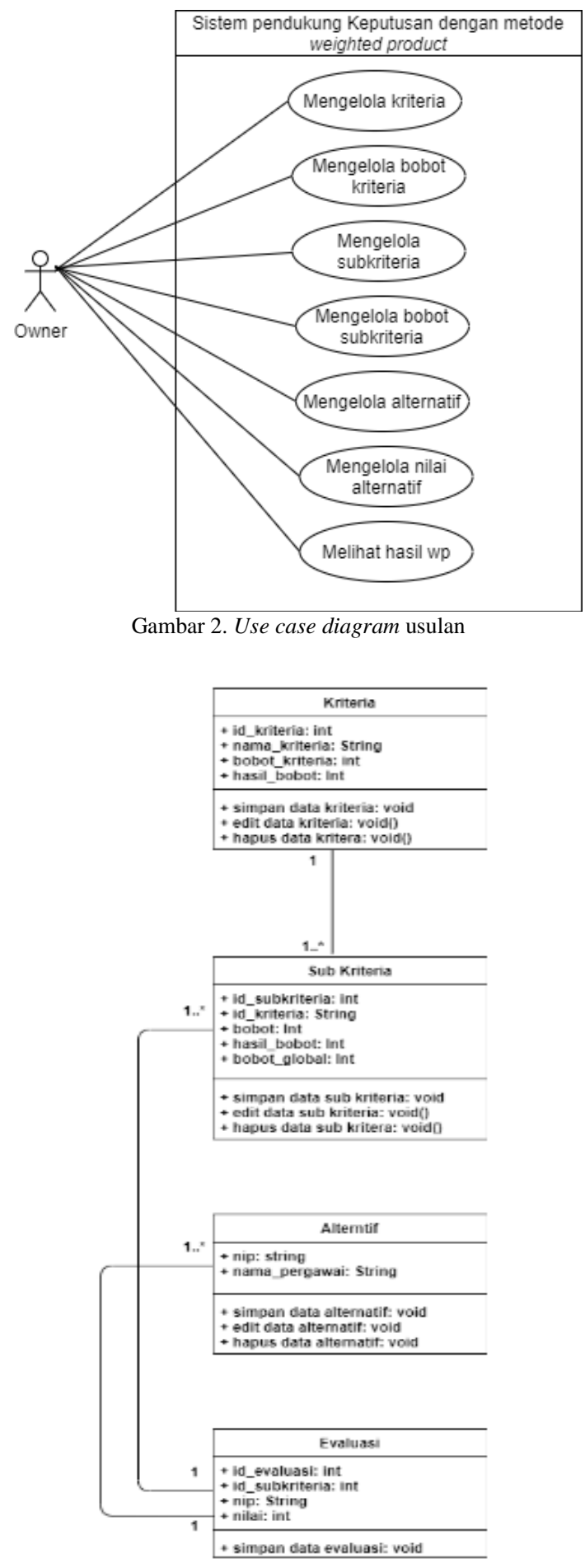

Gambar 3. Class Diagram Usulan

3) Impelementasi Aplikasi

Pada tahap ini aplikasi telah siap dioperasikan dan sudah sesuai dengan proses bisnis digambarkan dari langkah awal hingga langkah akhir. Pada implementasi ini akan di jelaskan beberapa tampilan dan keterangan fungsinya: 


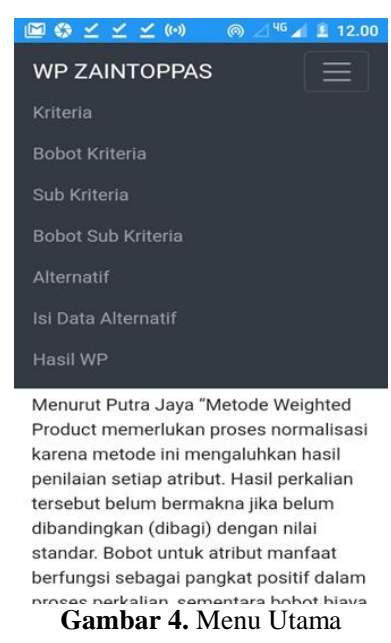

Gambar 4 merupakan halaman sub menu utama yang terdiri dari kriteria, bobot kriteria, subkriteria, bobot subkriteria, alternatif, isi data alternatif dan hasil wp

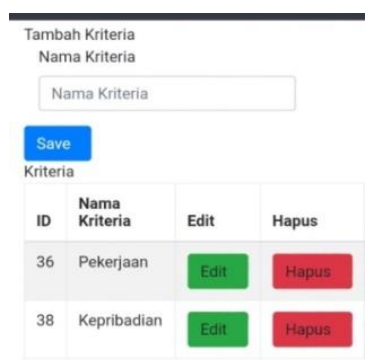

Gambar 5. Mengelola Kriteria

Gambar 5 merupakan halaman mengelola kriteria, Owner dapat menambahkan, Mengubah dan menghapus kriteria.

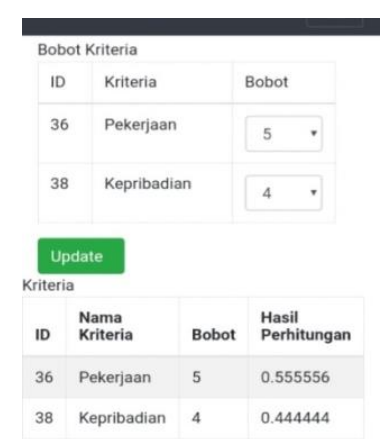

Gambar 6. Mengelola bobot kriteria

Gambar 6 merupakan halaman mengelola bobot kriteria, Owner dapat menambahkan, dan mengubah bobot kriteria.

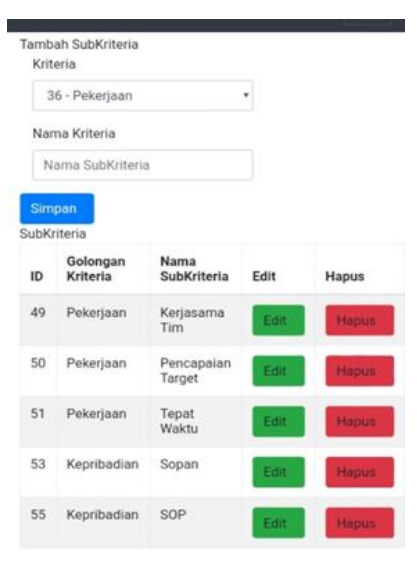

Gambar 7 Mengelola sub kriteria

Gambar 7 merupakan halaman mengelola sub kriteria, Owner dapat menambahkan, Mengubah dan menghapus sub kriteria.

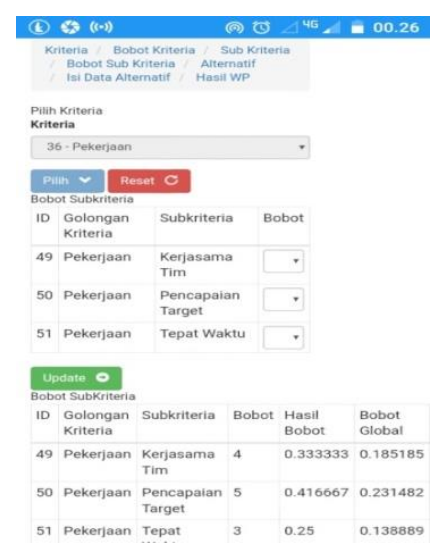

Gambar 8. Mengelola bobot sub kriteria

Gambar 8 merupakan halaman mengelola bobot kriteria, Owner dapat menambahkan, dan mengubah bobot sub kriteria.

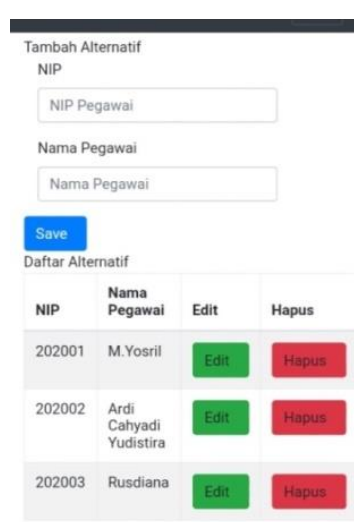

Gambar 9. Mengelola alternatif

Gambar 9 merupakan halaman mengelola alternatif, Owner 
dapat menambahkan, Mengubah dan menghapus alternatif.

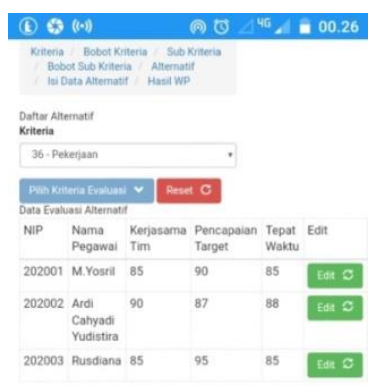

Gambar 10. Mengelola nilai alternatif

Gambar 10 merupakan halaman mengelola nilai alternatif, Owner dapat menambahkan, dan mengubah nilai alternatif.

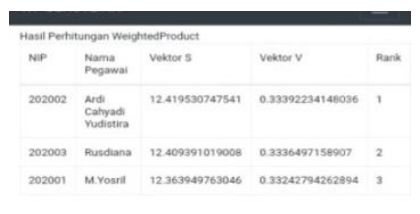

Gambar 11. Melihat hasil wp

Gambar 11. merupakan halaman hasil wp. Owner dapat melihat hasil perhitungan metode weighted product untuk memilih karyawan terbaik.

\section{KESIMPULAN}

Berdasarkan hasil penelitian dapat simpulkan bahwa :

- Hasil dari sistem pendukung keputusan menggunakan metode weighted product menghasilkan rekomendasi karyawan terbaik yang memiliki nilai vektor $\mathrm{V}$ tertinggi.

- Sistem pendukung keputusan dengan menggunakan metode weighted product menggunakan kriteria dan sub kriteria, dengan menghasilkan nilai bobot global dari hasil perkalian bobot kriteria dengan subkriteria., untuk kriteria dan sub kriteria dibuat tidak tetap sehingga kriteria dan sub kriteria dapat dirubah oleh Owner UMKM ZainToppas sesuai dengan kebutuhan.
- Terciptanya sistem pendukung keputusan ini dapat menghasilkan informasi karyawan terbaik yang berhak menerima reward yang berpotensi memacu kinerja karyawan menjadi lebih baik.

\section{DAFTAR PUSTAKA}

[1] S. Susiawan and A. Muhid, "Kepemimpinan Transformasional, Kepuasan Kerja dan Komitmen Organisasi," Pers. Psikol. Indones., vol. 4, no. 03, pp. 304-313, 2015.

[2] khukaim barkhowa Mokhammad, "Pengaruh kepemimpinan terhadap kinerja karyawan dengan kedisiplinan karyawan sebagai variabel intervening," J. Magisma, vol. 5, no. 1, pp. 24-37, 2017.

[3] B. Priambodo, N. Ani, and Y. Jumaryadi, "An efficient and affordable push strategy of mobile advertising for micro enterprises," Internetworking Indones. J., vol. 10, no. 2, pp. 43-48, 2018.

[4] V. Septiawan, "Reward Dan Punishment Sebagai Pemicu Kinerja Karyawan Pada Pt . Dunia Setia Sandang Asli Iv," vol. 8, no. 1, pp. 51-61, 2019

[5] C. Fiarni, E. M. Sipayung, and P. B. T. Tumundo, “Academic Decision Support System for Choosing Information Systems Sub Majors Programs using Decision Tree Algorithm," J. Inf. Syst. Eng. Bus. Intell., vol. 5, no. 1, p. 57, 2019.

[6] A. Setyawan, F. Y. Arini, and I. Akhlis, "Comparative Analysis of Simple Additive Weighting Method and Weighted Product Method to New Employee Recruitment Decision Support System (DSS) at PT. Warta Media Nusantara," Sci. J. Informatics, vol. 4, no. 1, pp. 34-42, 2017.

[7] Dona, K. Yasdomi, and U. Utami, "Sistem Pendukung Keputusan Karyawan Terbaik Menggunakan Metode Weight Product (WP) (Studi Kasus: Universitas Pasir Pengaraian)," vol. 4, no. 1, pp. 129-143, 2018 .

[8] I. Ardhiyanto, V. Lusiana, and N. Mariana, "Implementasi Metode ( Wp ) Weighted Product Pada Sistem Pendukung Keputusan Penilaian Karyawan Terbaik Di Pendanaran Hotel Semarang," Proceeding SINTAK, vol. 3, pp. 101-105, 2019.

[9] N. Hasanah and R. Priambodo, "Perancangan Sistem Pendukung Keputusan Prioritas Program Kerja Dengan Metode Simple Additive Weighting ( Saw )," J. Cendikia, vol. 18, no. X, pp. 349-358, 2019.

[10] E. Turban, A. EJ, and T. P. Liang, Decision Support Systems and Intelligent Systems edisi 7 Jilid 1. Yogyakarta: Andi, 2005.

[11] Diana, Metode dan aplikasi sistem pendukung keputusan, 1st ed. Yogyakarta: Deepublish, 2018.

[12] K. Savitha and D. C. Chandrasekar, "Vertical Handover decision schemes using SAW and WPM for Network selection in Heterogeneous Wireless Networks," Glob. J. Comput. Sci. Technol., vol. 11 , no. 9 , p. 7, 2011.

[13] N. Marpaung, M. Handayani, and R. Yesputra, "Sistem Pendukung Keputusan Pemilihan Dosen Terbaik Dengan Metode Weighted Product (WP) Pada STMIK Royal,”Semin. Nas. R. 2018, vol. 9986, no. September, pp. 267-270, 2018.

[14] K. Eliyen and F. S. Efendi, "Implementasi Metode Weighted Product Untuk Penentuan Mustahiq Zakat," InfoTekJar (Jurnal Nas. Inform. dan Teknol. Jaringan), vol. 4, no. 1, pp. 146-150, 2019.

[15] Oktafianto, E. Y. Anggraeni, and Suyono, "Sistem Pendukung Keputusan Perangkingan Sekolah Menengah Kejuruan (SMK) di Kabupaten Pringsewu Menggunakan METODE Weighted Product (WP," Expert, vol. 7, pp. 1-11, 2017.

[16] P. S. Ganney, S. Pisharody, and E. Claridge, "Software Engineering," in Clinical Engineering, Ninth Edit., Elsevier, 2014, pp. 133-170. 